\title{
Screening Outcomes of Hepatitis B and E among HIV Patients on HAART in Osogbo, South Western Nigeria
}

\author{
Bolaji E. Egbewale1, Victor 0. Mabayoje ${ }^{2 *}$, M. A. Muhibi ${ }^{3}$, A. F. Mustapha ${ }^{4}$, Calistus A. Akinleye ${ }^{1}$ \\ ${ }^{1}$ Department of Community Health, College of Health Sciences, Ladoke Akintola University of Technology, Osogbo, Nigeria \\ ${ }^{2}$ Department of Haematology and Blood Transfusion, College of Health Sciences, Ladoke Akintola University of Technology, Osogbo, \\ Nigeria \\ ${ }^{3}$ Department of Haematology, LAUTECH Teaching Hospital, Osogbo, Nigeria \\ ${ }^{4}$ Department of Medicine, LAUTECH Teaching Hospital, Osogbo, Nigeria \\ Email: `tunjimabs@gmail.com
}

How to cite this paper: Egbewale, B.E., Mabayoje, V.O., Muhibi, M.A., Mustapha, A.F. and Akinleye, C.A. (2016) Screening Outcomes of Hepatitis B and E among HIV Patients on HAART in Osogbo, South Western Nigeria. World Journal of AIDS, 6, 205217.

http://dx.doi.org/10.4236/wja.2016.64023

Received: September 5, 2016

Accepted: December 24, 2016

Published: December 27, 2016

Copyright $\odot 2016$ by authors and Scientific Research Publishing Inc. This work is licensed under the Creative Commons Attribution International License (CC BY 4.0).

http://creativecommons.org/licenses/by/4.0/ (c) (i) Open Access

\begin{abstract}
Background: The lives of patients living with HIV/AIDs have improved in terms of longer life expectancy and quality. This has seen the emergence of complications of the disease and the drugs such as metabolic syndrome and re-emergence of tuberculosis. Co-infection with other viruses especially the hepatic viruses has also become a major source of concern. The aim of this research is to determine the incidence of hepatitis $\mathrm{B}$ and $\mathrm{E}$ among this group of patients. Methods and Findings: Blood samples were collected from 156 consecutive HIV positive patients on HAART, informed consent having been obtained previously. The patients were screened both for hepatitis $\mathrm{B}$ and $\mathrm{E}$ using standard procedures. A questionnaire was administered to all participants. The results are illustrated with tables following analysis with SPSS version 10. It was found that $24.5 \%$ were positive for hepatitis $\mathrm{E}$ while $7.8 \%$ were positive for hepatitis B. It was also found that educational status was the only statistical significant variable for HEV co-infection. Taking the value of alanine transaminase to be 12 $\mathrm{U} / \mathrm{L}$ as upper limit of normal, the mean value for HEV positive patients obtained was 13.8U/L while for those HBV positive was 10U/L. Conclusion: From the findings, more emphasis should be placed on improving education of the populace. More research should be carried out to determine what subtypes of the viruses are present and their effects on the hepatic system using preferably non-invasive techniques. Also the variability of hepatic enzymatic activity needs more analysis.
\end{abstract}

\section{Keywords}

Aids, Transmission, Viral, HAART, Hepatic 


\section{Introduction}

Since the advent of highly active antiretroviral therapy (HAART) introduced in 1996 [1], there has been an increase in the quality and length of life of patients placed on these drugs. The disease condition acquired Immune deficiency Syndrome (AIDS) has gradually evolved into a chronic condition however with subsequent side effects of the drugs and side effects of AIDs itself emerging as the patients live longer. Complications of the drugs have been well documented e.g. Zidovudine and anaemia. Other well documented complications include metabolic syndrome (hypertriglyceridemia, low highdensity lipoprotein cholesterol, and insulin resistance). This has been shown to increase the risk of cardiovascular events in these groups of patients [2]. Drugs associated with this include starvudine [3], lopinavir/ritonavir. Other complications are co-infection with tuberculosis and co-infection with other viruses [4] [5] [6].

Co-infections with other viruses such as west Nile virus, cytomegalovirus and Parvovirus B19 have been well documented [7]. A lot of emphasis has been placed on co-infection with hepatitis $\mathrm{C}$ because of the effect of HIV/HCV has on the hepatic system. It could lead to liver fibrosis, cirrhosis and a particular aggressive form of hepatic carcinoma [4]. Since it is possible for other viruses to be present alongside HIV in a patient who is HIV positive, it is important to investigate such a patient for the presence of other viruses especially the hepatic viruses. Once HIV is diagnosed in a patient the patient is then screened for these viruses and managed based on the findings [5]. In a study carried out in our facility it was found that $23.2 \%$ were found to be co-infected with HCV [4]. These patients are therefore prone to the more aggressive effects of HIV/HCV mentioned above, and should be managed appropriately. In another study among the same group of patients increases of hepatic enzymes were also observed and a further study revealed that these patients were potentially prone on the long term to hepatic osteoarthropathy [5] [8] similar to findings obtained in other parts of the world. Interestingly it was noted that females were more prone than males to these adverse events.

A considerable amount of studies have been carried out worldwide on HIV/Hepatitis $\mathrm{C}$ virus (HIV/HCV) co-infection, and it would appear that more emphasis has been placed on this dual infection than has been on hepatitis B virus co-infection with $\mathrm{HIV}$ (HBV/HIV co-infection) even though they are both of significant clinical importance. However Hepatitis $\mathrm{B}(\mathrm{HBV})$ co-infection with HIV is another dual viral coinfection of significant epidemiological importance [9] [10]. Though it can also be transmitted via blood, sexual activity and sharing of needles among drug addicts are more common routes of infection with HCV. It is estimated that $10 \%$ of HIV positive individuals are also HBV positive. Complications associated with hepatitis $\mathrm{B}$ and $\mathrm{C}$ are currently among the leading causes of hospital admission and death in the HIVinfected population. Therefore, adequate management of hepatitis $\mathrm{B}$ and $\mathrm{C}$ infection is now being considered a priority in HIV-co-infected patients. HBV is the leading cause of chronic liver disease and a leading cause of death, accounting for up to half of all cases of cirrhosis and hepatocellular carcinoma [11]. 
An estimated 400 million people are infected with HBV, with the majority of cases occurring in regions of Asia and Africa where the virus is endemic. There, up to $70 \%$ of adults show serologic evidence of current or previous infection, and 8 to $15 \%$ have chronic HBV infection. In Nigeria high rates have been reported in various parts of the country. There is an increase in morbidity and mortality in HBV/HIV infected patients than in those infected with either virus alone. These co-infected individuals have progression to chronic hepatitis B almost five times faster than those infected with hepatitis B alone. They are also 17 more time likely to die than those infected with HBV virus alone. There are higher levels of hepatitis B viraemia and have a higher risk of cirrhosis and hepatocellular carcinoma. HBV/HIV co-infection is of particular significance in pregnant women. They have expression of HBV DNA and HBeAg which makes transmission to the fetus easier and more efficient. In general HIV immunosuppression can cause a reduction in HBV surface antibody such that the individual is unable to mount an effective defence leading to reactivation of chronic hepatitis $B$ and subsequent sequelae [12]-[17].

Human immunodeficiency virus (HIV) and hepatitis B virus (HBV) exact a high toll on infected patients. Both can lead to chronic disease, cancer, and death, and neither can be eradicated with the use of current therapeutic medication. Drug resistance often develops after patients have received treatment for some time and is usually followed by the loss of clinical advantages. Co-infection with the two viruses exacerbates the negative effects. Studies have revealed that co-infection with $\mathrm{HBV}$ is associated with lower CD4 counts [12]. Thus it is essential in a center such as ours dedicated to the prevention and management of HIV to determine the incidence of HBV/HIV in our group of patients.

It has been suggested that all HIV patients should be screened for HBsAg, and those found to be negative should undergo further screening for $\mathrm{HBcAb}$ and $\mathrm{HBsAb}$ as those would provide evidence of immunological control of previous infection or vaccination. All HBsAg-positive patients should be counseled about reducing the risk of $\mathrm{HBV}$ transmission to close contacts. It is known that HBV can be more infectious than HIV and can be transmitted to household contacts via dried blood, open cuts, and shared toothbrushes or razors. Sex partners, household members, children with close physical contact are also prone. Those who share injections, with the patient should be screened for $\mathrm{HBV}$ and vaccinated if they are not actively infected.

Hepatitis E virus (HEV) is another virus that can occur in association with HIV. It is a non enveloped RNA virus also belonging to the family hepeviridae. The route of transmission being feco-oral, Hepatitis E virus epidemics are therefore associated with poor sanitation and hygiene. Its incidence varies with geographical location. The virus has been successfully isolated in pigs and deer making it zoonotic. Being an emerging infection it has become of considerable significance worldwide, though it appears very little attention is being paid to the virus in Nigeria presently. However, studies from Ibadan in south west Nigeria have revealed infection rates as high as $12.2 \%$ [18]. HEV has a predilection for immune-compromised patients which somewhat distinguishes it 
from the other hepatitis viruses. These immune compromised patients could undergo an acute infection which could be missed clinically and biochemically [18].

Organ transplantation is becoming an increasingly frequent mode of treatment for a wide variety of diseases worldwide and in Nigeria transplant centers are emerging in various parts of the country involving both the public and private health sector, hence, the necessity for more emphasis on screening for the virus. As mentioned above an important sustaining condition for the survival of this virus in humans is immunoparesis [18].

Studies on HEV/HIV co-infection in Nigeria appear to be scanty and isolated. Though a study among health care workers (HCW) in Ibadan in south west Nigeria revealed higher levels of HEV-antibody (44\%) among HCW than controls [19].

A reason for this could be that HCW because of the nature and setting of their various occupations (nurses, lab. scientists, medical doctors, etc.) they are more prone to blood borne viral infections than other populations [20]. This also indicates that more studies need to be carried out regarding HIV and other viruses in our clinical instance especially those that are blood borne. Indeed it could be that we are on the threshold of a situation whereby hepatitis $\mathrm{E}$ is included among the mandatory viruses(HBV, $\mathrm{HCV}$, HIV) that need to be screened for before declaring a potential candidate "fit" as a blood donor, though much more indepth research and analysis need to be carried out. It is interesting to note that like HCV, HEV has also been reported as a nosocomial infection.

The prevalence of HEV in USA and Europe has been reported as being between $1 \%$ $5 \%$, while those reported in developing areas of the world range from $10 \%-100 \%$. In Asia and regions of northern Africa infections rates of between $22.5 \%$ to $100 \%$.

\section{Materials and Methods}

Study population: Blood samples were collected from 156 consecutive HIV positive individuals on antiretroviral therapy (ART) with adequate data from administered questioneers. The participants gave informed consent to be included in the study.

The study was carried out in Osogbo the capital city of Osun state in Nigeria. It is an urban setting with a population of 3,416,959. The residents are majorly Yoruba however there are other ethnic groups including Hausas, Igbos and those of Edo state origin. The weather pattern is typically tropical, periods of heavy rain fall alternating with dry spells. For the diagnosis of HIV testing kits from three different manufacturers were utilized such as Unigold, Statpak and Determine using recognized standard methods. In diagnosing $\mathrm{HBV}$ infection, third generation enzyme immunoassay kit produced by DIAPRO (Italy) was used where-in the serum specimen was diluted with DILSPE and $100 \mu$ of the diluted specimen, alongside the negative controls in triplicate and positive controls were added to different wells, leaving the first well as blank. After the micro plate was incubated and wells washed, all the wells were treated with enzyme conjugate except the first blanking well. The micro plate was incubated again and the chromogen/substrate mixture was added after the second washing. The reactions were stopped 
with sulphuric acid and the optical density (OD) was read at $450 \mathrm{~nm}$ immediately. The cut-off value for the batch was determined and individual results were interpreted as negative $(<0.9)$; positive $(>1.1)$ and equivocal $(0.9-1.1)$ as appropriate. For the diagnosis of HEV infection, using reagents and wells supplied by Diapro, Italy, wash buffer was diluted 1 to 20 with distilled water. A $50 \mu$ leach of positive control, negative control and specimen was added into their respective wells. Then, $50 \mu$ HRP-Conjugate antibody was added to each well except the Blank. The plate was incubated for $60 \mathrm{mi}-$ nutes at $37^{\circ} \mathrm{C}$ and the wells were washed 5 times with wash buffer, allowing the micro wells to soak for 30 - 60 seconds. A volume of $50 \mu \mathrm{l}$ of TMB solution A and $50 \mu \mathrm{l}$ TMB solution $\mathrm{B}$ was added into each well including the Blank, and the plate was incubated at $37^{\circ} \mathrm{C}$ for 10 minutes avoiding light. The enzymatic reaction between the TMB solutions and the HRP-Conjugate antibody produced blue color in positive control and anti-HEV positive sample wells.

Using a multichannel pipette, $50 \mu \mathrm{l}$ stop solution was added into each well. Intensive yellow color developed in positive control and HBsAg positive sample wells. The absorbance was read at $450 \mathrm{~nm}$, using $630 \mathrm{~nm}$ as reference wavelength. The results were then subjected to statistical analysis using SPSS version 10 .

\section{Results}

Of all the 156 participants 128 were female and 28 male. The majority $37.8 \%$ had attained secondary education, while $33.3 \%$ had been to university. Eight percent reported having no education at all. Self-employment was the main source of income in most cases at $65.4 \%$, while $3.8 \%$ were unemployed (Table 1 ). Twenty six (16.7\%)were civil servants and $4.5 \%$ had achieved professional status. $82.7 \%$ were married, while $9.6 \%$ were single and $7.7 \%$ widowed. There was no evidence of organ transplantation throughout the study (Table 2). Majority of the participants had a CD4 count above 500 (62.8\% Table 2). All those positives for hepatitis B had been through the educational system (Table 3).

Only $17.3 \%$ agreed to having had blood transfusion previously while $17.9 \%$ reported using condoms with every sexual encounter. $23.1 \%$ used condoms occasionally while $45.5 \%$ denied using condoms at all.

Of the travel history, the majority $87.2 \%$ had no significant travel history. Only $9.0 \%$ had a positive travel history. There was no history of organ transplant in any of the cases. $26.3 \%$ percent had pregnancy less than two years ago and $37.2 \%$ reported pregnancy over four years ago. Reviewing the infections as dual infections with HIV i.e. HIV and $\mathrm{HBV}$, for HBV/HIV dual infection the majority was married and $7.8 \%$ of these were positive for HBV. Regarding education the majority of positive cases were among those who had attained tertiary education. Most (78\%) had no history of blood transfusion and of those positive (HIV/HBV) only 1 (3.6\%) agreed to using condoms for every sexual encounter.

Most of them (92.6\%) had no travel history. For dual infection with HEV according to marital status the widowers had the highest rate of infection at $16.7 \%$, educational 
Table 1. Socio-demographic distribution of HIV study population.

\begin{tabular}{cc}
\hline Sex & \\
Female & $128(82.1)$ \\
Male & $28(17.9)$ \\
Religion & \\
Christianity & $87(55.8)$ \\
Islam & $69(44.2)$ \\
Occupation & \\
Artisan & $15(9.6)$ \\
Professional & $7(4.5)$ \\
Civil servant & $26(16.7)$ \\
Self employed & $102(65.4)$ \\
Unemployed & $6(3.8)$ \\
Marital status & \\
Single & $15(9.6)$ \\
Married & $129(82.7)$ \\
Widowed & $12(7.7)$ \\
Educational status & \\
Primary & $37(23.7)$ \\
Secondary & $59(37.8)$ \\
Tertiary & $52(33.3)$ \\
None & $8(5.1)$ \\
\hline
\end{tabular}

Table 2. Distribution of predisposing factors to Hepatitis B \& E among HIV positive respondents.

\begin{tabular}{cc}
\hline Transfusion & \\
No & $129(82.7)$ \\
Yes & $27(17.3)$ \\
Condom use & $28(17.9)$ \\
Always & $36(23.1)$ \\
Occasionally & $71(45.5)$ \\
Not at all & \\
Travel history & $136(87.2)$ \\
No & $14(9.0)$ \\
Yes & \\
Pregnancy & $41(26.3)$ \\
$<2$ Years ago & $13(8.3)$ \\
Years & $58(37.2)$ \\
$>4$ Years & $150(96.2)$ \\
History of diarrhoea & $6(3.8)$ \\
No & \\
Yes & $156(100)$ \\
Organ transplant & \\
No & $26(16.7)$ \\
CD4 count & $32(20.5)$ \\
Below 200 & $98(62.8)$ \\
200 - 499 &
\end{tabular}

status ( $\mathrm{p}=0.002$ ) was the only statistically significant variable and the highest percentage of those positive for HEV had no form of education at all. Those with secondary school education had the lowest rate of infection at $3.4 \%$. Of the transfusion history, $7.4 \%$ had a positive history. $24.5 \%$ were positive for HEV while $7.8 \%$ were positive for 
Table 3. Association between socio-demographic characteristics and presence of hepatitis B.

\begin{tabular}{ccccc}
\hline Risk factors & $\begin{array}{c}\text { Hepatitis B } \\
\text { Negative (\%) Positive (\%) }\end{array}$ & Chi-square value & P value & Remark \\
\hline Marital status & $15(100.0) 0(0.0)$ & & \\
Single & $119(92.2) 10(7.8)$ & 2.24 & 0.327 & NS \\
Married & $12(100.0) 0(0.0)$ & & \\
Widowed & $8(100.0) 0(0.0)$ & & \\
Educational status & $35(94.6) 2(5.4)$ & 0.766 & \\
None & $55(93.2) 4(6.8)$ & & \\
Primary & $48(92.3) 4(7.7)$ & & \\
Secondary & $27(100) 0(0.0)$ & & \\
Tertiary & $119(92.2) 10(78)$ & 2.236 & \\
Transfusion & $27(96.4) 1(3.6)$ & & \\
Yes & $33(91.7) 3(8.3)$ & & \\
No & $67(94.4) 67(94.4)$ & & \\
Condom use & $126(92.6) 10(7.4)$ & & \\
Every & $14(100.0) 0(0.0)$ & & \\
Occasionally & & & \\
Not at all & & & \\
Travel & & & \\
No & & & \\
Yes & & & \\
\end{tabular}

HBV. Of those positive for both HEV and HBV alanine transaminase levels were not statistically significant.

\section{Discussion}

Our study population revealed that 128 were female and 28 were male. This is not surprising as all studies we have carried out on HIV expose the higher incidence of HIV in females than males which has been established in other studies. Overall the majority of our subjects were married (82.7\%) (Table 1). 24.5\% were positive for HEV. This is on the high side when compared to $11.7 \%$ obtained by Hassing et al. in a study carried out in Holland in 2014. This might be explained by the more affluent society that study was carried out with cleaner healthier environment and higher quality of health care. It was also noted that HEV positivity was equally prevalent among different CD4+ groups which is similar to our findings (Table 2) [21]. It should be mentioned at this point that HEV infection has been linked with poverty in the developing world such as Nigeria. [22]. Increasing incidence of co infection of HEV and HIV with age has been reported in South Iran, $47.7 \%$ occurring in those over 50 years.

The only statistically significant epidemiological association of HEV infection was with educational status. This is strikingly similar to studies carried out in other parts of Nigeria. In Plateau state Nigeria formal education was also one of the significant variables associated with HEV [23]. The more educated the society is, the more likely higher emphasis would be placed on positive environmental issues such as cleanliness, positive attitude to health care and other important factors ensuring a healthier environment. Other risk factors identified by the study included marital status, location and farming as a profession. In our study marital status revealed that the highest number of 
HEV positive cases were among those who were widowed and married (Table 4). HEV infection is an acute self limiting infection that is responsible for up to $20 \%$ of deaths in pregnant women. None of our female participants were pregnant and reports of the infection among pregnant women are somewhat low [24]. However in India high infection rates have been reported with increased severity of infection [25] [26]. This further underlines the fact that location, surroundings etc. have a significant role to play in HEV infection rates.

Blood transfusion is also a risk factor for HEV infection. Of those positive for HEV in our study, 2 (7.4\%) (Table 2) had a positive history of blood transfusion. Transfusion safety has been of paramount importance for the transfusion services worldwide and with time the transfusion safety has been constantly improving due to mandatory screening of blood and blood products with regular introduction of more sensitive tests. Currently screening of blood and blood products for HEV is not done and there are also no recommendations. But the question is largely unanswered whether parenterally transmitted HEV is a risk to transfusion safety. It may well be that screening for HEV would be added to the battery of screening tests especially as SOTs (solid organ transplants) become a more frequent treatment option.

In our cohort there was no history of organ transplants, however this cannot escape mention because it is well known and accepted that patients with reduced immunity are prone to the effects of HEV infection. In a study in the Netherlands, it was found that patients with solid organ transplants (SOTs) were at a definite higher risk of HEV infection.

Table 4. Association between socio-demographic characteristics and presence of hepatitis E.

\begin{tabular}{|c|c|c|c|c|}
\hline Risk factors & $\begin{array}{c}\text { Hepatitis E } \\
\text { Negative (\%) Positive (\%) }\end{array}$ & Chi-square value & $P$ value & Remark \\
\hline Marital status & & \multirow{4}{*}{2.612} & \multirow{4}{*}{0.271} & \multirow{4}{*}{ NS } \\
\hline Single & $15(100) 0(0.0)$ & & & \\
\hline Married & $119(92.2) 10(7.8)$ & & & \\
\hline Widowed & $10(83.3) 2(16.7)$ & & & \\
\hline \multicolumn{5}{|c|}{ Educational status } \\
\hline None & $5(62.5) 3(37.5)$ & \multirow{4}{*}{14.398} & & \\
\hline Primary & $32(86.5) 5(13.5)$ & & \multirow{3}{*}{0.002} & \multirow{3}{*}{$S$} \\
\hline Secondary & 57 (96.6) $2(3.4)$ & & & \\
\hline Tertiary & $50(62.5) 2(3.8)$ & & & \\
\hline \multicolumn{5}{|l|}{ Transfusion } \\
\hline No & $119(92.2) 10(7.8)$ & \multirow{2}{*}{0.004} & \multirow{2}{*}{0.951} & \multirow{2}{*}{ NS } \\
\hline Yes & 25 (92.6) $2(7.4)$ & & & \\
\hline \multicolumn{5}{|l|}{ Condom use } \\
\hline Every & $28(100) 0(0.0)$ & \multirow{3}{*}{3.886} & \multirow{3}{*}{0.274} & \multirow{3}{*}{ NS } \\
\hline Occasional & 33 (91.7) 3 (8.3) & & & \\
\hline Not at all & $63(88.7) 8(11.3)$ & & & \\
\hline \multicolumn{5}{|l|}{ Travel out } \\
\hline No & $126(92.6) 10(7.4)$ & \multirow{2}{*}{0.709} & \multirow{2}{*}{0.702} & \multirow{2}{*}{ NS } \\
\hline Yes & $13(92.9) 1(7.1)$ & & & \\
\hline
\end{tabular}


Nine of 12 patients who had SOT were treated postoperatively with a tacrolimusbased regimen, which has been associated with increased risk for HEV infection [27]. In time SOTs as a treatment option in this part of the world would increase as health care systems strive to improve in quality along with best practices worldwide.

In our study, $7.8 \%$ of the HIV positive patients were co-infected with HBV and were all married. This is somewhat lower to figures obtained in Italy where $15.4 \%$ of cases were found to be co-infected [28]. However, coming down to Africa in Burkinafaso, $12.17 \%$ out of 115 pregnant HIV positive patients were found to be positive for HBV. Though in Mali only a co-infection rate of $1.13 \%$ was obtained [29]. In South Africa, co-infection rates as high as $20 \%$ were detected by investigators [29]. Another study in Nigeria revealed co-infection rates of $11.9 \%$. It can be deduced from this wide swings of co-infection rates that co-infection is largely dependent on particular environments. This in turn would now involve variables within the location such as hygiene, access to quality healthcare and educational status among others. However unlike with HEV, educational status was not statistically significant $(\mathrm{p}=0.002)$ (Table 3$)$. It has been suggested that HBV infection is more likely to occur in HIV infected individuals than in none infected persons probably due to reduced immunity. Interestingly it has also been suggested that HBV infection routes differ to those of HIV. Studies have linked HIV transmission to stronger association with sexual activity, while transmission routes involving $\mathrm{HBV}$ are majorly vertical. At this point it may be relevant to note that transmission routes for hepatitis $\mathrm{C}$ virus infection (HCV) have been strongly associated with parenteral routes. The point being that even though all three viruses may be present in an individual, each virus has its own unique and "preferred" transmission route. This is very important especially when it regards developing methods aimed at reducing or preventing transmission altogether [30]-[35]. The study revealed that levels of alanine transaminase in those both positive for HEV and HBV were not particularly significant (Table 5). It was found that $24.5 \%$ were positive for hepatitis $\mathrm{E}$ while $7.8 \%$ were positive for hepatitis B. It was also found that educational status was the only statistical variable for $\mathrm{HEV}$ co-infection. Alanine transaminase levels were not significantly affected in this study. Taking $12 \mathrm{U} / \mathrm{L}$ as upper limit of normal, the mean average for HEV positive patients was $13.8 \mathrm{U} / \mathrm{L}$ while for those $\mathrm{HBV}$ positive was $10 \mathrm{U} / \mathrm{L}$ (Table 5 and Table 6). Patients positive for $\mathrm{HEV}$ and revealing normal alanine transaminase levels are not unknown as was shown in a study carried out in Australia [36]. Another study suggested that persistent elevation of alanine transaminase levels were suggestive of chronic cases of HEV infection [37]. That study also seemed to indicate that co-infection with $\mathrm{HCV}$ was more likely to be the cause of raised alanine transaminase levels even in the presence of HEV [37]. The majority of our patients had CD4 counts of above 500. This should not be unexpected as they were all on HAART and clinically stable with absence of recurrent fever, candidiasis or other clinical indicator of immune deficiency. However it should be noted that the British HIV association has stated in its treatment options for co-infected patients with HBV, that even those with CD4 counts above 500 should be given the option of commencing treatment. 
Table 5. Mean AGE and ALT levels in those both positive and negative for HBV.

\begin{tabular}{ccc}
\hline & ALT & Age \\
\hline Positive & 10 & 40.28 \\
Negative & 10.6 & 41.30 \\
\hline
\end{tabular}

Table 6. Mean age and alt levels in those both positive for HEV.

\begin{tabular}{ccc}
\hline & ALT & AGE \\
\hline Positive & 13.08 & 47.83 \\
Negative & 9.76 & 39.72 \\
\hline
\end{tabular}

\section{Conclusion}

As HIV/AIDS patients continue to live longer due to the introduction of highly active antiretroviral therapy (HAART) in 1996, the emergence and relationship of co-infection with other viruses especially the hepatic viruses and their adverse contributions to the infection have become global causes of concern. However, more research has to be undertaken to increase our knowledge in this part of the world on the effect of HIV coinfection with other viruses in order to improve treatment outcomes and reduce transmission rates. The established role of educational status in the incidence of HEV cannot be over emphasized. More should be done to increase the educational status of the populace more so in developing countries.

\section{References}

[1] O’Bryan, T.A., Okulicz, J.F.' Bradley, W.P., Ganesan, A., Wang, X. and Agan, B.K. (2015) Impact of the Highly Active Antiretroviral Therapy Era on the Epidemiology of Primary HIV-Associated Thrombocytopenia. BMC Research Notes, 8, 595. https://doi.org/10.1186/s13104-015-1548-3

[2] Lambert, C.T., Sandesara, P.B., Hirsh, B., Shaw, L.J., Lewis, W., Quyyumi, A.A., Schinazi, R.F., Post, W.S. and Sperling, L. (2015) HIV, Highly Active Antiretroviral Therapy and the Heart: A Cellular to Epidemiological Review. HIV Medicine, 6, 411-424.

[3] Diouf, A. and Cournil, A., Groupe d'étude de la Cohorte ANRS 1215 (2014) Prevalence of Metabolic Complications after 10 Years of Antiretroviral Treatment in Senegal. Bulletin de la Société de Pathologie Exotique, 4, 234-237. https://doi.org/10.1007/s13149-014-0349-6

[4] Mabayoje, V.O., Muhibi, M.A., Akindele, R.A., Akinleye, C.A., Mabayoje, P.S. and Babatunde, O.S. (2013) Hepatitis C Virus Co-Infection among People Living with HIV/AIDS in a Nigerian Teaching Hospital. HIV and AIDS Review, 4, 102-105.

https://doi.org/10.1016/j.hivar.2013.09.003

[5] Mabayoje, V.O., Akindele, R.A., Akinleye, C.A., Muhibi, M.A., Owojuyigbe, T.O. and Fadiora, S.O. (2013) Epidemiological Factors and Liver Enzymes in Patients Co-Infected with HIV/AIDS in a Tertiary Teaching Hospital. Standard Scientific Research and Essays, 14, 409-414.

[6] Pawlowski, A., Jansson, M., Sköld, M., Rottenberg, M.E. and Källenius, G. (2012) Tuberculosis and HIV Co-Infection. PLOS Pathogens, 2, Article ID: e1002464.

https://doi.org/10.1371/journal.ppat.1002464 
[7] Allain, J.-P., Stramer, S.L., Carneiro-Proietti, A.B.F., Martins, M.L., Lopes da Silva, S.N., Ribeiro, M., Proietti, F.A. and Reesink, H.W. (2009) Transfusion-Transmitted Infectious Diseases. Biologicals, 2, 71-77. https://doi.org/10.1016/j.biologicals.2009.01.002

[8] Mabayoje, V.O., Muhibi, M.A., Akinleye, C.A. and Akindele, R.A. (2015) Calcium and Total Bilirubin Levels in Patients Co-Infected with HIV and Hepatitis C Viruses in Lautech Teaching Hospital, Osogbo, South West Nigeria. BJMMR, 1, 72-81. https://doi.org/10.9734/BJMMR/2015/15205

[9] Vargas, J.I., Jensen, D., Sarmiento, V., Peirano, F., Acuña, P., Fuster, F., Soto, S., Ahumada, R., Huilcaman, M., Bruna, M., Jensen, W. and Fuster, F. (2015) Presence of Anti-HBc Is Associated to High Rates of HBV Resolved Infection and Low Threshold for Occult HBV Infection in HIV Patients with Negative HBsAg in Chile. Journal of Medical Virology, 4, 639-646.

[10] Chandra, N., Joshi, N., Raju, Y.S., Kumar, A. and Teja, V.D. (2013) Hepatitis B and/or C Co-Infection in HIV Infected Patients: A Study in a Tertiary Care Centre from South India. Indian Journal of Medical Research, 6, 950-954.

[11] Ahuja, S., Malhotra, S., Chauhan, A. and Hans, C. (2013) Seroprevalence of Hepatitis B and C Co-Infection in HIV Positive Patients from a Tertiary Care Hospital. Journal International Medical Sciences Academy, 26, 91-92.

[12] Ojide, C.K., Kalu, E.I., Ogbaini-Emevon, E. and Nwadike, V.U. (2015) Co-Infections of Hepatitis B and C with Human Immunodeficiency Virus among Adult Patients Attending Human Immunodeficiency Virus Outpatients Clinic in Benin City, Nigeria. Nigerian Journal of Clinical Practice, 4, 516-521. https://doi.org/10.4103/1119-3077.151790

[13] Highleyman, L. (2003) HIV and Hepatitis C Coinfection. BETA, 15, 32-44.

[14] Piliero, P.J. and Faragon, J.J. (2002) Case Report. Hepatitis B Virus and HIV Coinfection. AIDS Reader, 10, 443-448.

[15] Thio, C. (2004) Hepatitis B Virus Infection in HIV-Infected Persons. Current Hepatitis Reports, 3, 91-97. https://doi.org/10.1007/s11901-004-0015-8

[16] Leeratanapetch, N. and Suseangrut, W. (2008) Hepatitis B Virus and Hepatitis C Virus CoInfection with HIV Patients at Khon Kaen Hospital. Khon Kaen Hospital Medical Journal, 32, 229-238.

[17] Mohammadi, M., Talei, G., Sheikhian, A., Ebrahimzade, F., Pournia, Y. and Ghasemi, E. (2009) Survey of Both Hepatitis B Virus (HBsAg) and Hepatitis C Virus (HCV-Ab) Coinfection among HIV Positive Patients. Virology Journal, 6, 202. https://doi.org/10.1186/1743-422X-6-202

[18] Odaibo, G.N. and Olaleye, D. (2013) Hepatitis E Virus Infection in HIV Positive ART Naïve and Experienced Individuals in Nigeria. World Journal of AIDS, 3, 216-220. https://doi.org/10.4236/wja.2013.33029

[19] Ola, S.O., Odaibo, G.N., Olaleye, D. and Ayoola, E. (2012) Hepatitis B and E Viral Infections among Nigerian Healthcare Workers. African Journal of Medicine and Medical Sciences, 4, 387-391.

[20] WHO (2002) Guideline for Hand Hygiene in Health-Care Settings. Morbidity and Mortality Weekly Report, Vol. 51, No. RR-16.

[21] Hassing, R.J., van der Eijk, A.A., Lopes, V.B.' Snijdewind, I.J., de Man, R.A., Pas, S.D. and van der Ende, M.E. . (2014) Hepatitis E Prevalence among HIV Infected Patients with Elevated Liver Enzymes in the Netherlands. Journal of Clinical Virology, 4, 408-410. https://doi.org/10.1016/j.jcv.2014.05.009

[22] Kumar, S., Subhadra, S., Singh, B. and Panda, B.K. (2013) Hepatitis E Virus: The Current 
Scenario. International Journal of Infectious Diseases, 4, s228-s233.

https://doi.org/10.1016/j.ijid.2012.11.026

[23] Junaid, S., Agina, S. and Abubakar, K. (2014) Epidemiology and Associated Risk Factors of Hepatitis E Virus Infection in Plateau State, Nigeria. Virology, 5, 15-26.

https://doi.org/10.4137/vrt.s15422

[24] Rostamzadeh Khameneh, Z., Sepehrvand, N. and Khalkhali, H.R. (2013) Seroprevalence of Hepatitis E among Pregnant Women in Uremia, Iran. Hepatitis Monthly, 11, e10931.

[25] Beniwal, M., Kumar, A., Kar, P., Jilani, N. and Sharma, J.B. (2003) Prevalence and Severity of Acute Viral Hepatitis and Fulminant Hepatitis during Pregnancy: A Prospective Study from North India. Indian Journal of Medical Microbiology, 3, 184-185.

[26] Medhat, A., El-Sharkawy, M.M., Shaaban, M.M., Makhlouf, M.M. and Ghaneima, S.E. (1993). Acute Viral Hepatitis in Pregnancy. International Journal of Gynecology \& Obstetrics, 2, 25-31. https://doi.org/10.1016/0020-7292(93)90768-R

[27] Kamar, N., Garrouste, C., Haagsma, E.B., Garrigue, V., Pischke, S., Chauvet, C., Dumortier, J., Cannesson, A., Cassuto-Viguier, E., Thervet, E., Conti, F., Lebray, P., Dalton, H.R., Santella, R., Kanaan, N., Essig, M., Mousson, C., Radenne, S., Roque-Afonso, A.M., Izopet, J. and Rostaing, L. (2011) Factors Associated with Chronic Hepatitis in Patients with Hepatitis E Virus Infection Who Have Received Solid Organ Transplants. Gastroenterology, 5, 1481-1489. https://doi.org/10.1053/j.gastro.2011.02.050

[28] Morsica, G., Ancarani, F., Bagaglio, S., Maracci, M., Cicconi, P., Cozzi Lepri, A., et al. (2009) Occult Hepatitis B Virus Infection in a Cohort of HIV-Positive Patients: Correlation with Hepatitis C Virus Co-Infection, Virological and Immunological Features. Infection, 5, 445-449. https://doi.org/10.1007/s15010-008-8194-9

[29] Askari, A., Hakimi, H., Ahmadabadi, B. and Hassanshahi, G. (2014) Prevalence of Hepatitis B Co-Infection among HIV Positive Patients: Narrative Review Article. Iranian Journal of Public Health, 6, 705-712.

[30] Benhamou, Y. (2004) Antiretroviral Therapy and HIV/Hepatitis B Virus Coinfection. Clinical Infectious Diseases, 2, S98-S103. https://doi.org/10.1086/381451

[31] Rustgi, V.K., Hoofnagle, J.H., Gerin, J.L., Gelmann, E.P., Reichert, C.M., Cooper, J.N. and Macher, A.M. (1984) Hepatitis B Infection in the Acquired Immunodeficiency Syndrome. Annals of Internal Medicine, 6, 795-797. https://doi.org/10.7326/0003-4819-101-6-795

[32] De Lalla, F., Rizzardini, G., Rinaldi, E., Santoro, D., Zeli, P.L. and Verga, G. (1990) HIV, HBV, Delta-Agent and Treponema Pallidum Infections in Two Rural African Areas. Transactions of the Royal Society of Tropical Medicine and Hygiene, 84, 144-147. https://doi.org/10.1016/0035-9203(90)90412-8

[33] Ahmed, S.D., Cuevas, L.E., Brabin, B.J., Kazembe, P., Broadhead, R. and Verhoeff, F.H. (1998) Seroprevalence of Hepatitis B and C and HIV in Malawian Pregnant Women. Journal of Infection, 3, 248-251. https://doi.org/10.1016/S0163-4453(98)91983-1

[34] Tibbs, C.J. (1995) Methods of Transmission of Hepatitis C. Journal of Viral Hepatitis, 3, 113-119. https://doi.org/10.1111/j.1365-2893.1995.tb00016.x

[35] Henderson, D.K. (2003) Managing Occupational Risks for Hepatitis C Transmission in the Health Care Setting. Clinical Microbiology Reviews, 3, 546-568. https://doi.org/10.1128/CMR.16.3.546-568.2003

[36] Yong, M.K., Paige, E.K., Anderson, D. and Hoy, J.F. (2014) Hepatitis E in Australian HIVInfected Patients: An Under-Recognised Pathogen? Sex Health, 4, 375-378. https://doi.org/10.1071/SH13198

[37] Kenfak-Foguena, A., Schöni-Affolter, F., Bürgisser, P., Witteck, A., Darling, K. and Kovari, 
H. (2011) Hepatitis E Virus Seroprevalence and Chronic Infections in Patients with HIV, Switzerland. Emerging Infectious Diseases, 6, 1074-1078.

https://doi.org/10.3201/eid/1706.101067

Submit or recommend next manuscript to SCIRP and we will provide best service for you:

Accepting pre-submission inquiries through Email, Facebook, LinkedIn, Twitter, etc.

A wide selection of journals (inclusive of 9 subjects, more than 200 journals)

Providing 24-hour high-quality service

User-friendly online submission system

Fair and swift peer-review system

Efficient typesetting and proofreading procedure

Display of the result of downloads and visits, as well as the number of cited articles

Maximum dissemination of your research work

Submit your manuscript at: http://papersubmission.scirp.org/

Or contact wja@scirp.org 